\title{
Public Relations Strategies to Built Financial Technology (Fintech) Awareness
}

\author{
The 'Koinworks' Way \\ Debby Natalia, Mohammad Shihab \\ Communication Studies \\ President University \\ Cikarang, Indonesia \\ shihab@president.ac.id
}

\begin{abstract}
Traditional way of financing has been shifted by financial technology. This situation is supported by demands coming from unbanked people and small and medium enterprises (SMEs). By the end of 2016, only $36 \%$ of Indonesian adults have an account at the formal financial institution, while 49 million SMEs units were not bankable as shown on Indonesia Fintech Report 2016. As one of financial technology (fintech) players in Indonesia, KoinWorks provides peer-to-peer (P2P) lending system. However, because of the new concept of financial industry, people still have a low awareness of fintech institution, especially Koinworks. This company aims to acquaint to public the advantages of fintech institution utilizing public relations $(P R)$ roles and strategies. Its PR department is expected to reach communication goals, including increasing the brand awareness. This research employed qualitative approach and the data were primarily collected through in-depth interviews with four purposively-chosen participants. This study concluded that all Marketing PR strategies were executed by marketing and public relations and strategies that were optimized to build the brand awareness were events, news, speeches, and sponsorships.
\end{abstract}

Keywords—-public relations; strategies; fintech; Koinworks

\section{INTRODUCTION}

From the last two decades, Indonesia's financial industry has shifted due to the fast technology growth and development, from traditional financial system (bank driven) to the financial technology (consumer driven). Financial technology (fintech) enables more players to emerge in Indonesia financial sector. A 2016 research of Daily Social ID and Indonesia's Fintech Association (IFA) reported that only $18,5 \%$ of 1000 participants used fintech service [1].

In fact, a deeper insight of the fintech market in Indonesia can be seen from the demands coming from unbanked people and Small-Medium Enterprises (SMEs). Only 36\% of Indonesian adults have an account at the formal financial institution and 49 million SMEs not yet bankable. Responding this condition, one of the fintech branches peer-to-peer (P2P) lending, aims to enable people to access financial services using online technology. P2P lending service enables people to apply for an easier and affordable loan as well as to provide investment platform [2].
KoinWorks is one of the financial technology companies in Indonesia. Established in 2016, KoinWorks focuses on peer-topeer lending service. It aims to provide financial support to Indonesia SMEs.

Public relations (PR) can be the most effective tools when it comes to a brand reputation or image to the public. PR attempts to create an image and channel certain messages. PR is also expected to penetrate the message to the relevant publics, according to the company's intention. As Public Relations Society of America defined, "Public Relations as the practice of managing communication between an organization and its publics." To build awareness of the company, PR needs to create long-term and short-term plan to achieve the awareness. In other words, Public Relations has to be able to manage the company's brand image to the targeted public as well as optimizing the brand recognition. This means PR may fit the fintech needs, through its strategy to approach the target market and build the company brand recognition.

Therefore, KoinWorks realizes the importance of public relations roles to raise awareness, communicate company's messages to the public, and establish mutual relationships between the company and its publics. Although the establishment of the Koinwork's PR department is still recent, its role cannot be underestimated. The PR department is responsible to plan and execute strategies to raise the awareness as well as to maintain communication and relations with both internal and external publics.

Recently, many researchers have studied the PR roles and strategies in building brand recognition and awareness. Mikáčová and Gavlaková identified the role of PR in the branding of Coca-Cola [3]. The study resulted that the PR became the 'legs' of the company to enhance the brand quality of the product. They also built the brand attitudes and reputation by telling credible stories and providing support for the truth of a brand is advertising images.

Another study was conducted by Ratna Sari on PR roles and strategies in the rebranding of Le Hotel Beringin. She analyzed how PR of Le Beringin Hotel managed the brand alteration from Hotel Beringin to Le Beringin Hotel Salatiga [4]. However, the study concluded that the applied strategies 
did not meet the goal because only a few people noticed the brand alteration of Hotel Beringin.

As far as the researchers have reviewed, none of the studies focused on fintech services. Thus, this research will describe the roles and strategy of PR department. This research aims to explain how the PR officer manages the brand awareness of KoinWorks as a fintech company based on PR roles as expert advisor, communication facilitator, problem-solving process facilitator, communication technician. In addition, the research aims to describe the marketing PR strategies through publications, advertising, promotions, media relations, events, news and community involvements.

\section{RESEARCH METHOD}

This research used the descriptive qualitative. The primary goal of qualitative inquiry is to reveal and interpret how public relations affect society; this includes the communication process between stakeholders, publics, practitioners, communities, and individuals [5]. Hence, to get in-depth comprehending, the researchers purposively selected employees of KoinWork's Marketing Department, who manage the marketing communication and public relations strategies, as the key informants. In addition to the informants, two customers of KoinWorks were also involved to get additional insights and information about the PR activities. All the interviews were transcribed and the results were categorized based on certain categories. Then, researcher interpreted the data and constructed the meaning $[5,6]$.

\section{RESUlT AND DISCUSSION}

KoinWorks is a startup fintech company established in October 2015. In August 2016, KoinWorks launched their first products and officially began its operation. The core program is to provide loan service for various purposes, including business, health, and education. Becoming a fintech with a P2P lending system, KoinWorks becomes an online platform connecting lenders and borrowers.

The researchers found that KoinWorks' PR department worked under marketing division. The PR department was handled by a PR manager who worked together with social media manager and content writer.

PR Department in the company was formed in December 2016. Appointed PR Manager, Debby Lufiasita (Lufi) had experienced as a PR officer in reputable banking institutions, such as Permata Bank and Bank of Indonesia. As PR manager, the core strategy was to create brand awareness. Its roles in the company more or less correlated with marketing strategies as PR and Marketing shared the same department. The PR Department was expected to build a positive image of KoinWorks in the eyes of publics, including the customers, potential lenders, and potential borrowers.

According to Lufi, the first goal of PR in this startup industry was to succeed in communicating the idea that KoinWorks would be a financial solution to its public. It was reciprocal with the Marketing Department's goal, which was customers' acquisition. Therefore, most of the strategies consisted of the combination of marketing and public relations strategies to obtain certain goals in brand awareness, which led to customers increase.

Lufi and Jonathan intended to widen their brand acquisition by the means of supportive coverages of press, TV, radio or even online news provider. In the collaboration with the Marketing Department, the PR Department usually used the advantage of trending things and crave story, while Marketing focused on how to sell the products. Nevertheless, these two contrary, yet reciprocal departments can collaborate and support each other.

\section{A. Roles of Public Relations}

Public relations has certain roles and functions. Dozier and Broom, identified the PR roles as expert prescriber, communication facilitator, problem solving process facilitator, and communication technician [7].

1) Expert Advisor: The expert advisor is one of the four roles of PR. The expert advisor works independently and does not take any input from other organization stakeholders. KoinWorks's PR manager worked under Marketing Division. Thus, the PR manager could not work independently because it affiliated with other division to take any decision.

Jonathan, the Head of Marketing Department, considered that PR could support marketing with different channel and medium. They agreed that marketing and PR did not share the same concept, but they might share the same objectives. Marketing and PR goals were to increase public's acknowledgment of KoinWorks' services.

2) Communication Facilitator: Another role of public relations is the communication facilitator. The role facilitates and maintains the communication process between the public and organization. Lufi stated that communicating with the public, directly and indirectly, was the PR duty.

"Yes indeed, it is the PR duty (communication process in KoinWorks). As I stated earlier, if we do not have one voice, the fault is in our internal communication. It is not possible to blame our business development or customers' service. It must be the PR. However, if we have a brand manager, we may work together. It means all communication flow, oral or written, things to be published needs PR consent, " Lufi shared.

KoinWorks did not have a brand manager but a social media manager. Therefore, all social media were not administrated Lufi or PR department. Most of the time, she discussed with the social manager to determine the best way to answer or communicate with the public through social media. The public often asked through social media because many of them did not know how the fintech worked. Lufi and Jonathan realized this situation and hence use the media as the tools to deliver their updated news.

3) Problem-solver: Many researchers believe the role of problem-solving process facilitator has similarity with the expert advisor role. The main difference is problem-solving facilitator works with other departments and stakeholder to solve problems. Usually, they create a long-term plan for the organization. 
Lufi and Jonathan mostly worked and shared plan together. Jonathan admitted that any crisis occurred in KoinWorks would be discussed and solved using PR method and manner.

"Besides spreading the news, we also have crisis management, because we manage many media, for instance, social media. If the customer found a loss or miscalculation, they'd usually ask through our social media. PR helps us craving the story, how we should answer them and give the good response," shared Jonathan.

4) Communication Technician: As communication technician, the PR Department had executed many of PR materials. Some of the materials were prepared by the PR manager. But, some contents were also prepared by the writer from Jonathan's team. The materials prepared were media lists, press releases, publications, and captions.

\section{B. Public Relations Strategies}

Several major tools mostly used in Marketing PR, such as publications, events, sponsorships, news, speeches, public service activities, and identity Media [8].

1) Publications: Publication is a fundamental strategy for a startup business, including KoinWorks, to build awareness. The PR manager used publications to increase the awareness of KoinWorks. All publications were made in the forms of printed and digital, such as blog, e-newsletter, and social media.

KoinWorks had their own blog, which was published on their website. This blog was managed by the content writer and the SEO manager, not the PR Department. Another publication, e-newsletter, was also written by the SEO manager.

For digital publications, KoinWorks utilized various social media to share publications. These included Facebook, Instagram, YouTube and LinkedIn. All of these social media were not managed by the PR manager, but the Social Media manager. The social media manager was responsible to publish all news and updates from KoinWorks. For example on Youtube, the manager shared their event previews and storythemed video. It was also applied on Instagram, Facebook, and LinkedIn. Meanwhile, the printed publications were brochures and banners.

2) Events: KoinWorks had been operating for 1,5 years. But, it had a plenty of events throughout the year, such as press conferences, media interviews, seminars, and workshops. In the last March, the company hosted an event named 'Her Action'. It was a workshop and a seminar to support International Women Day on 8th March.

Next month, KoinWorks organized two press conferences. The first conference was to announce a new partnership with RS Premiere Bintaro as they also launched the 'KoinSehat'.

The other one was to launch their campaign called ARTificial Intelligence. This campaign was objected to accentuate KoinWorks brand, particularly in the lifestyle aspect. The campaign ran for almost three weeks started from 12th - 30th April. As a part of the campaign, the company exhibited the special artworks created by selected college students. The PR manager said that KoinWorks wanted to enhance the art and lifestyle aspects, and combined the aspects with the business to increase awareness toward the company.

The exhibition attracted media attention and was covered by some media.

Other than special events, KoinWorks also organized regular events focused on targeted communities, specifically the SMEs. The researcher found that they developed three communities for woman-entrepreneurs, local hand-made businesses, and online sellers. The company hosted a community event every month to expand the business network and to educate the mission of the company.

"Mostly the topic is about how they (the borrowers) use their loans and the impacts to their business. There are still plenty of people have no idea what the money is for", said Jonathan.

3) Sponsorship: KoinWorks contributed to several events as a sponsor. The sponsorship, in return, would give the company some spaces to build awareness.

“...we had sponsored several events, such as IndoNetwork. Why we were sponsoring them? It is because we are startup. We want to expand our name. As long as the event is good and affect our products, I mean affect our borrowers and lenders, why should not we try it?, " Lufi shared.

As the PR manager, Lufi believed that by collaborating and sponsoring any event, KoinWorks would benefit from the event.

4) News: Producing newsworthy information is a tactic to attract journalists. Both PR and Marketing managers agreed that mass media were the right tool to raise the awareness of KoinWorks. KoinWorks produced newsworthy articles related to new promotion, feature, partnership, event, etc.

Lufi as the PR manager knew well how to approach media. She was very aware that she had to manage a good relationship with the media, especially personal relationship with the journalists.

5) Speeches: In several occasions, the KoinWorks executives would have speeches or statements about the company. The PR manager was responsible to prepare the key messages and to brief the speaker.

Since its first launching of KoinWorks in 2016, the cofounder of KoinWorks, Benedicto Haryono, was appointed as spokesperson of KoinWorks. He, whom also served as Chief Executive Officer (CEO), always showed up when KoinWorks had to meet the press.

Besides his roles as the CEO and Co-founder, Haryono comprehended most of the system and technical matters within KoinWorks. The Marketing manager, Jonathan, shared that the CEO held a strong education background and had experienced in various managerial and chief levels. Showing his strong background was a tactic to set him as a trusted-source for journalists. 
"Startup company never accentuate its brand at first, it is farly possible, because there is no media wants to cover, like 'what is KoinWorks?' So personally, I think the right tactic is by using our CEO, who is also owner of KoinWorks, " Jonathan shared.

6) Public Service Activities: KoinWorks did not organize a special community involvement program. But, the PR manager shared that the 'ARTificial Intelligence' contained a charity program, which cooperated with Yayasan Cinta Anak Bangsa (YCAB) foundation.

The event gained some amount of fund through the bidding of exhibited artworks during the exhibition. The PR manager claimed that they had collected more than 54 million rupiahs and donated the fund to the YCAB foundation.

"So generally, we don't have any CSR campaign, but we made an event and contribute to education," explained Lufi.

7) Identity media: People may distinguish KoinWorks from its logo, icon, colors, and the products. The KoinWorks logo was presented in ' $\mathrm{W}$ ' shape, colored with red and blue as the corporate color. In the shape, two dots represented both borrowers and lenders.

KoinWorks had three core products, such as KoinBisnis, KoinPintar, and KoinSehat. The word 'Koin' became the icon of KoinWorks, so the public could easily recognize that it was a part of KoinWorks.

"Other P2P services focus only one loan product while we have some varieties of loan products. KoinBisnis is for business financing, KoinPintar is for education loan, and KoinSehat is for health loan," said Lufi.

\section{CONCLUSION}

This study described the role and strategy of KoinWork's PR Department to build brand awareness as a fintech industry in Indonesia. All Marketing PR strategies were executed by marketing and public relations and strategies that were optimized to build the brand awareness were events, news, speeches, and sponsorships.

The research suggested KoinWorks to emphasize other Marketing PR strategies to get better brand awareness. Moreover, further study in fintech business is required to explore how the publics see fintech business as a new source of financing.

\section{REFERENCES}

[1] DailySocial.id. "Indonesia's Fintech Report 2016". Retrieved March 10, 2018, (online) available at: https://dailysocial.id/report/post/indonesiasfintech-report-2016. (2016).

[2] Mikáčová, L., \& Gavlaková, P. "The role of public relations in branding". Contemporary Issues in Business, Management and Education 2013.

[3] Ratnasari, D. "Roles and Strategy of Public Relations in building brand awareness of Le Beringin Hotel Salatiga”. 2012.

[4] Daymon, C. \& Holloway, I. "Qualitative Research Methods in Public Relations and Marketing Communications". New York: Routledge. 2011.

[5] Creswell, J. W. "Educational Research", 3rd edition. New Jersey: Pearson. 2008.

[6] Lee, N. M. "The role of new public relations practitioners as social media experts" (Doctoral dissertation, San Diego State University). 2013.

[7] Kotler, P. \& Keller K.L. "Marketing Strategy 14th edition". New Jersey: Pearson. 2012.

[8] Williams-Grut, O. "This is how a new crop of companies is trying to reinvent banking". (Online) available at: http://uk.businessinsider.com/how-fintech-transforming-finance-20159/?IR=T. 2015,. 